\title{
3 A`s of Reflexive Design Thinking in Architecture
}

\author{
Gokce Ketizmen Onal ${ }^{1}$ \\ ${ }^{1}$ Department of Architecture, Eskisehir Osmangazi University, Odunpazari, Eskisehir, Turkey \\ Correspondence: Gokce Ketizmen Onal, Department of Architecture, Eskisehir Osmangazi University, Bademlik \\ Campus 26030, Odunpazari, Eskisehir, Turkey.
}

Received: October 16, 2018

doi:10.11114/ijsss.v6i11.3708
Accepted: October 22, $2018 \quad$ Available online: October 23, 2018

URL: https://doi.org/10.11114/ijsss.v6i11.3708

\begin{abstract}
The present study intends to discuss reflexive design thinking in architecture with respect to the interactions between three main dimensions and with the aim to disclose the interrogative considerations in architecture; the identical features, in various actions and contexts. The main objective is to uncover new connections and new potentials that are equally essential in architectural thinking, the inquiry through theory construction and the connection to practice, as well as the basic attitude of initiating thinking on iterative possibilities.

Within this scope, the present study develops a reflexive design approach in architecture, by layering the theoretical and practical dimensions, taking creative generation and transformation into consideration. Accordingly, the whole structure of the value systems is accepted as reflexive architectural thinking that is formed by three dimensions: Architect, Action, Artifact. These contents, accepted as the main subjects of research approach, are each evaluated in the light of knowledge systems and conditions. The present study utilizes this research perspective in order to analyze and discuss the basic dimensions of design thinking in a reflexive way, through presenting a discourse on its meanings, context and contents. Therefore, the present study an attempt in architectural design-based research to develop a reflexive methodology for re-interpreting and re-formulating the relation between theory and practice.
\end{abstract}

Keywords: reflexive design, design-based research, architectural design thinking, 3A`s of reflexive design thinking

\section{Introduction}

Theory and practice are the roots of architecture. Architecture is the system of contradictions by its abstractness and concreteness. At the interface of these two contexts, the implications of the study portray the features of reflexive design research approach intended to figure out the new connections and patterns between theory and practice. In recent years field of design research strongly developed, where research perspective is described as thinking and action of architecture; to gain and to create knowledge and examined and integrated for the practice. Design related research is a way of emphasizing axiomatic practices that create values as connectivity and meaningfulness of design in the broader context of shaping human environments (Buchert, 2014). Since 1960, there exist numerous attempts in design-based research, which counter to purely scientific and technical rationality, promote holistic knowledge, aim to uncover the openly creative in generation of ideas through preventing the research data from being poured into a given theoretical mould. (Anderson, 1989). Reflexivity, therefore, provides the perspective for being self-critical, as Etherington (2004) argues, by creating "... a dynamic process of interaction within and between ourselves and the data that inform decisions, actions and interpretations at all stages of research."

Reflexivity, as being focused on the self and the ongoing intersubjectivities, is also a process that attempts to identify, do something about, and acknowledge the limitations of the research through anticipating on its location, subjects, process, theoretical context, data and its analysis (Ruby, 1980). Design research in architecture, positioned between practice and theory, cover the characterization and expression of the practices and the context, the actors and the disciplines as complete contributors. Within the context of such interaction, reflexivity could help to develop a self-critical way of thinking in design practice, supports to develop better understanding of research approaches and particularly provides stimulus for creative process in the context of design. (Buchert, 2014). In order to evaluate, comprehend and interpret architectural settings as a context and practice, research perspective of reflexive design is capable of providing the layering of theoretical and practical dimensions that take creative generation and transformation into consideration, as well as the special forms of cognition and their functions in relation to contemporary knowledge systems and cultural conditions (Buchert, 2014:24) 
Given the scope above, the present study intends to discuss reflexive design thinking with respect to the interactions between three main dimensions: architect, action, artifact and with the aim to disclose the interrogative considerations in architectural design thinking process; its identical features, in various actions and contexts. Disclosing new connections and potentials that are equally essential in architectural design thinking is the significant objective especially with respect to the inquiry through theory construction and the connections to practice, as well as development of the basic attitude of initiating thinking on iterative possibilities. Hence, the whole structure of the value systems is accepted as reflexive architectural thinking that is formed by three basic contents: Architect, Action, Artifact (3A`s of reflexive thinking in architecture). Thus, these contents are accepted as the main subjects of research approach and each is evaluated within the scope of reflexive design thinking.

It is essential to develop an analytical description of the three contents through a theoretical perspective that consider architecture as a creative process, together with the special forms of cognition and their functions in relation to contemporary knowledge systems. Within this scope, the present study proposes a reflexive design approach titled 3A`s of reflexive thinking in architecture developed with respect to the potentials and connections between the three dimensions of reflexive thinking in architecture: architect, action and artifact.

As indicated above, the present study undertakes an approach to propose a novel way of criticizing and re-theming the main dimensions of architectural design thinking in a reflexive way, by focusing on the relation and connections between its basic dimensions. Each dimension is structured through a particular definition and each content is interpreted and evaluated in a reflexive way. Moreover, it is emphasized that reflexive design features certain design-based research study and comprises an integrative way to interpret the essence of each contents with regard to theory and practice. Initially, it is essential to discuss reflexive design in order to elucidate its approach and relate this approach with the intentions of the present study. Consequently, the three dimensions within the reflexive design perspective are discussed. It is aimed that such research would provide guidance to design-based research particularly focusing on architectural thinking developed within the framework of reflexive design.

\section{Reflexive Design}

In the last decade, the domain of design research developed strongly and the research perspectives were commonly based on the elucidation of thinking and action in architecture in order to gain and to create knowledge to be examined for and integrated in practice. The reflexivity concept is of increasing prominence in professional practice literature, particularly with respect to uncertainty discussed within the scope of social, as an important feature of professional discretion and ethical practice. Accordingly, researchers such as Pierre Bourdieu (Bourdieu \& Wacquant, 1992), (Bourdieu, 1990), Michael Polanyi (1962), Donald Schön (1983), Ulrich Beck (1994, 2003), Margaret S.Archer (2007, 2010) , Niklas Luhmann $(1990,1995,2000)$ provided notable contributions on the theoretical and the conceptual background of reflexivity. Moreover Howe \& Langdon (2002), Grim \& Rescher (2012), Finlay \& Gough (2003), Etherington (2004), Ruby (1980), Shacklock \& Smyth (1998), Roulston (2010), Brown, Sawyer \& Norris (2016), Mann (2016), Woolgar (1998), Buchert $(2014,2016)$ contributed to the research domain with essential studies on reflexivity as a research approach, social theory and reflexive design.

In order to describe the meaning, content and intentions of the reflexivity, it is essential to understand the roots of the concept. Pierre Bourdieu discusses that the term reflexivity should have a mediating effect as an individual and collective, self-criticial way of thinking in design practice (Bourdie, 1996; as cited in Buchert, 2013:34). Moreover Bourdieu, establishing own discourse on Foucault and Barthes, identifies reflexivity to a large extent with the systematic uncovering of unthought, intuitive, embodied categories which themselves are preconditions of conscious practice (Bourdieu and Wacquant, 1992). In this sense, it is significant to realize that reflexivity is a self-critical way of thinking where subjectivity is the main research methodology. It provides the perspective for researchers for being selfcritica through creating "a dynamic process of interaction within and between our selves and our participants, and the data that inform decisions, actions and interpretations at all stages of research" (Etherington, 2004: 36). Reflexivity, which focuses on the self and ongoing intersubjectivities, is also a process that attempts to identify, do something about, and acknowledge the limitations of the research: namely, its location, subjects, process, theoretical context, data and its analysis. (Ruby, 1980: 154). As these attempts counter to purely scientific, promote holistic knowledge and aim to uncover the openly creative in generation of ideas basically concerning self-referencing. As Etherington (2004: 19) emphasizes, the new paradigm research methodologies facilitated a more reasonable use of the self in research in the last decade. Adopting a self-referencing approach comprises the potential to provide a novel way of thinking and interpreting the facts about us and the world around us.

According to Etherington (2004:19) reflexivity is an aptitude to notice our responses to the outside world, other people and events, and to use such knowledge to inform our actions, communications and understandings. Etherington (2004:19) further argues that reflexivity requires an awareness of individual responses and the ability to decide on the 
utilization of these responses, along with the awareness on the personal, social and cultural contexts of the immediate environments of an individual and the impact of these contexts on the interpretation of the world.

According to Ruby (1980) the process of reflexivity is an attempt to identify, do something about, and acknowledge the limitations of the research with respect to its location, subjects, process, theoretical context, data and analysis, and accounts for the acknowledgement for the construction of knowledge that takes place in the world and does not position itself apart from it. Ruby (1980) asserts that "...being reflexive in doing research is part of being honest and ethically mature in research practice that requires researchers to 'stop being 'shamans' of objectivity" (p. 154). Buchert (2016) describes reflexive research perspective, with respect to architecture discipline, as designing and planning for spatial questions as a specific field of thinking and action of architecture to create knowledge that is examined and integrated for practice. She also pointed out that this re-theming could provide stimulating opportunities for the practice and self-understanding of the discipline in academic and societal building-related contexts. It also creates significance for the connectivity and meaningfulness of design in the broader context of shaping human environments.

Reflexive design provides the opportunity to step back from specific expectations and requirements, through a high degree of open-endedness. Such approach involves theory construction and a connection to practice, as well as a basic attitude of not necessarily answering questions but also raising them, not to merely delineate subject areas but to outline and conceptualize innovative formats, or in a more simpler expression: to think differently about design and research and how they interrelate (Buchert, 2014: 10) Furthermore, reflexive design creates a basis for developing implicit and explicit knowledge, therefore facilitates an appropriate nuance in descriptions that do not neglect the architectural while covering secondary technical aspects or morphology (Janson, 2014: 124). Aspects of architecture are based on complementary interplay of objective spaces and subjective experiences (Janson, 2014:106). Furthermore, reflexive design focuses on practice in order to qualify the situational reaction as a sense of feedback during the design process, for instance, through the particular reaction to program, location and technical and constructional requirements and as an open work process that incorporates the generation of ideas as well as various conditions, dialogs and cooperation's (Buchert ,2014:26). Considering Buchert's (2014) explanation it is possible to assert that reflexive design is an integrative way to interpret a particular reaction to the essence of design ideas with respect to theory and practice.

As a reflection of these connections, reflexive design forms a significant framework for the questioning, testing and production of knowledge. It combines design and research and seeks to connect with notions of science by pursuing and disclosing the interrogative attentiveness in various actions and contexts to a consciously sought-after practice and the genesis of findings. New connections and new potentials are equally important in creative mixing practices (Buchert, 2016).

Based on these explanations the study utilizes reflexive design perspective to evaluate and re-theme the basic contents and factors of architectural design thinking. The most important purpose in this attempt is to discuss the very well-known dimensions, which are considered as the basic dimensions of design-based research, in a new perspective.

\section{3A`s of Reflexive Design Thinking in Architecture}

Architecture is as an open - reflexive process that ingenerates three basic dimensions of architectural design: architect, artifact and action. Within such interaction, it is fundamental to improve re-theming of these concepts through exploring the design practice and theoretical background and consider architecture as a creative process, along with the significance of special forms of cognition and their functions in relation to contemporary knowledge systems. The analysis model, 3A`s of reflexive design thinking in architecture, was developed within the potentials and connections between the three dimensions of architectural thinking. With respect to these definitions, the present study evaluates each dimension, developed by reflexive design research perspective, in order to acknowledge the reflexive dimensions of architectural design thinking. Thus, it would be possible to propose a framework that could provide a theoretical and also methodological basis for re-theming and evaluating architectural design thinking, since the scope is to analyze and discuss architectural design thinking parameters.

Architectural design is different from the rest of design typologies and comprises a unique epistemological practice and a unique way of knowing that result from a complex process of conceptual negotiations. (Piotrowski, 2001, p. 40). Architects solve technical problems and try to bring together abstract issues in an exceptional conceptual reliability. Nonetheless, architects facilitate a process which depictions of the design artifacts attain a symbolic and socio-cultural sense. Such process is the most important aspect of architecture, where the creation activity occurs with inhabited reality formed in the images retrieved from memory or imagination. Piotrowski (2001: 41) explains these procedures as conceptual negotiations that involve the exchange between different modes of thought and points of view - between verbal and visual interpretations, for example, or between universal scientific laws and the kind of understanding that a particular design process reveals. Furthermore, Piotrowski (2001: 41) explains that, architect produces conceptual sketches, physical models, functional diagrams, technical drawings, cost analysis spreadsheets, and verbal explanations 
- supports this process of negotiation. In this way, by testing the spatial and material attributes of architecture, an architect explores the complexity of issues and factors that shape a prospective building. These practices are more than emblematic, they are constitutive, and chief among those timeless practices is design. (Conway \& Roenisch, 2005)

Architecture is the aggregation of elements. It is the aggregation of things, places, time, senses, memory, meaning, weather, expectations, and hopes. It differs from art and literature deals with the realities and everyday life. Michael Hays (2010:12) examines architecture as a way of negotiating the real, through intervening in the realm of symbols and signifying processes at the limit if the social order itself, hence architecture could be considered as a specific kind of socially symbolic production, whose primary task is the construction of concepts and subjects positions rather than making of things. (Hays, 2010). Moreover, Hays (2010:1) describes architecture as the "set of operations that organize formal representations of the real, and hence rather than merely being invested with an ideology by its creators or users, it is ideological in its own right-an imaginary solution to a real social situation and contradiction."

Adopting a similar perspective, Buchert (2014) states that architecture always undertakes the task of shaping the human habitat and has a fundamental influence on individuals' daily physical environment and therefore, comprises different possibilities when compared to the fine arts due to its degree of freedom and its constructive and technical restrictions. Buchert (2014:46) further argues that, architecture is a mediator, a horizon between the inhabited environment and the human that allows individuals to position and orientate themselves through mental and physiological foundations and associations.

Architecture, with its social, cultural, ontological, conceptual, constructional, technical, ideological, functional, representational and metaphorical features, is formed mainly through three domains: architect, action and artifact. All these domains are evaluated as the main sources and dimensions of architectural thinking and are evaluated in the light of reflexive design perspective in the present study. In this scope, reflexivity emerges as an important source in acknowledging a particular type of insight and cognitive content where it represents a reference and involvement with the theoretical and practical features of architecture. Here, the basic aim of reflexive design is to retain research findings openly creative in the generation of ideas that focuses on the layering of discourse and actions and to indicate the reciprocal nature of empirical and rational references (Buchert,2014).

Within these contents and targets three dimensions were chosen to express the reflexive assets of architectural design thinking, since reflexivity is accepted as a self-referencing system that is focused on intersubjectivities. The limitations to the reflexive design perspective and these subjectivities will be discussed respectively in the light of knowledge systems and conditions, since they constitute the key parameters of a creative open design system.

\subsection{Architect}

The word "architect" derives from the Greek phrase meaning "master builder," being archos; the 'chief' and tekton meaning the 'builder' (Conway \& Roenisch, 2005, p. 13). Conway \& Roenisch (2005:13) described the architect's work as not only designing but also making estimates, managing works, controlling costs, acting as an agent between the client and construction workers and even promoting speculative development. In the nineteenth century the work of many architectural practices included surveying, providing bills of quantities, arranging leases and assessing rents, as well as designing. Engineers had the mission to design machinery and structures to house them. The reasons of these changes are related to the changing practice of building in the mid-eighteenth century, transformations in building technology and the emergence of new types of building. In the process, what we understand by the term 'architect' also had a change in meaning. (Conway \& Roenisch, 2005, p:13,14). As Renier et.al (2009:90) stated that once the architect was the baumeister, with a central position within the building process. Now they are constrained to their core activity, designing. Additionally, Renier et.al (2009:90) make a classification that an architect operates as a system integrator at two levels, first as a designer and a coordinator in construction and second, as a driver for innovation beyond the level of an individual building.

Distinct from these definitions, Donald Schön (1983), utilizes reflection paradigm to the end that the architect becomes a researcher in the practice. He asserted that architect as a researcher, is not dependent on the categories of established theory and technique but constructs a new theory of the unique case. He expresses two approaches to establish this point of view, through the two action types he developed: Reflection-in- action and reflection-on-action. He claims that 'when someone reftects-in-action, he becomes a researcher in the practice context' (Schön,1983: 68). Schön identifies the researcher as the individual who does not disconnect thinking from doing, deliberating the way to a decision, which he/she must later convert to action.

Based on Schon's ideas, Aura, Katainen, \& Suoranta (2002:78) express the architect as a researcher who identifies main problems or concerns in the practice and apply the strategic plan for action and observes and evaluates this action. The authors (2002) continue to explain the task of the architect as a researcher with the ability to reflect the former findings on the results and make the necessary changes for the solution of the problem. Aura, Katainen, \& Suoranta (2002) explain this 
research process starting from the first step towards the steps of improvement, however, more importantly they indicate that the process is followed by a new cycle in the action research spiral, not in a linear sequence.

The present study, based on reflexive design perspective, evaluates the architect as a reflexive design researcher, who is not only a creative designer but also a researcher equipped with the task to construct a new theory or technique, similar to the claims of Schön indicated above. As a reflexive design researcher, the architect needs to evaluate design process not only as a linear design task, but also a reverse inquiry process. It is significant that the architect as a reflexive researcher need to propose a new way of creative perspective, a design research, where new theory, a model is proposed. In addition, it is essential not to separate doing from thinking, deliberating to a decision, which later needs to be converted to action.

\subsection{Action}

The action dimension, basically focusing on the creative generation and transformation process, is actualized within the light of theoretical and philosophical content of the design-based research. Design-based research is a new way of accentuating often self-evident practices. As described earlier, reflexive design provides a new way of evaluating design approaches where the process is appraised as a creative open work process that provides the layering of theoretical and practical dimensions, (Buchert, 2014).

Given the above framework of discussions, it becomes possible to consider creative design action as a design-based research process of an open creative cognitive action, which involves theory construction and a connection to practice. The architect -as the reflexive design researcher- does not concentrate only on theorising his or her practice, but also uses the design element as a tool, a research tool in order to achieve a primary relation to the phenomenon researched (Aura, Katainen, \& Suoranta, 2002). According to Aura, Katainen, \& Suoranta (2002:76) "the architect-researcher uses preliminary designs in the same way as another research would use questionnaires for purposes of empirical research. The design represents in this sense the empiria of design-based research, if and when empiria are defined as an important tool for the researcher's thought processes.". Furthermore, Aura, Katainen, \& Suoranta (2002) argue that design is a theoretical practice amenable to research either through theorising (practice-based research approach) or through establishing a dialogue between theory and design (design-based research approach) and define design-based research action as a reflective process of conceptual and material elements in the manner of a hermeneutic cycle.

In the present study architectural design is taken into consideration as a creative open action where the accomplishment of a design usually happens over a period of time, in stages, or with the possibility of repetition. Designing is a kind of action where the practice moves in a conceptual space between the (completely) disordered and the ordered in the manner of more systematic consideration from the theoretical perspective in retrospect in order to outline a space of knowledge (Buchert, 2016). Here, design as a reflection process means the analysis of the products by focusing on the process of achieving them. In the context of the reflection practice, rooted from Schön`s reflective design theory, design is a research action which is shaped by a variety of thinking systems such as delineating, implicating, interpreting, modifying, consolidating and intensifying. These actions admitted as the creative actions of a design that allows the designer to become the researcher that constructs a unique case and/or theory. As a nonlinear progress, these dimensions of design action constitute a repetitive and reflexive structure that acts as a contextual, situational, generative and progressive position, rooted in the overall condition of the creative mixture of designing and researching, explicating and reflecting on the forms of knowledge involved, and the implicit and explicit, and their combinations.

Delineating; Definition of design parameters environmental features, users, values, program are discussed.

Implicating: Implication of positive worldview in to the visions of future. Presentation of images, which already exist in the mind of the designer, evaluation of those images.

Interpreting: Evaluation of those ideas, and back to the collection of more data, presentation of more ideas, and apparent insights the designer has into the nature of the problem and its potential solutions,

Modifying: Collection and development of alternative ideas, analysing those alternatives, Evaluation of ideas, Selection of the most appropriate solution.

Consolidating: Presentation of ideas, which are collected and generated, design and practice mutual relation, design process proceeds during construction activity.

Intensifying: Generation and selection of construction ideas, supervision, revision and evaluation of the post-occupancy

These steps are considered as developing thinking phases that occur in a spiral manner, not in a linear way. The design action in a research process can start over from beginning. Moreover, as Piotrowski (2001) states, due to its dual nature, design process is clearly different from that of problem solving, which, even at its most inventive, it is based on a scientific paradigm - an assumption that a task becomes a problem that can be resolved when its objectives and limitations are well defined and design never stops until the design artifact is built up. 


\subsection{Artifact}

Artifact, is the response to the word building or product that includes cultural or historical interest. It is the quantity and quality of creative production (something new). Hence, the artifact is admitted as the proper definition of the architectural design product aesthetically, but also socially, philosophically, and technologically.

According to Silvetti (1998) architecture delineates its place and its part in the spheres of the production of knowledge and the production of meaning, as well as in the technical production of artifacts as being within the social practices. He believes that the artefact regarded as the technical-ideological practice, since it renovates both matter and man's consciousness and utilizes both techniques and human relations (Silvetti, 1998: 277). Based on such approach, it is possible to evaluate the artifact as the tool that reflects the design knowledge, through an ideological, social, cultural tangible form.

Artifact, recognized as the reflection of the design-research in the present study, is something other or more than the fulfilment of one programmatic theory. The artifact is open to other interpretations; it has a quasiautonomy relative both to any given theory or interpretation and is relative to external factors (Hays, 1998). Being as one of the main dimensions of reflexive design thinking, artifacts needed to be evaluated as the part of the communication system within the knowledge and practice of architecture. It is the tangible form of ideas, which is designed as a tool for expressing whole dimensions of thinking systems such as theoretical, sociological, cultural, and programmatic. Due to this concern and in the light of Schumacher's (2012) opinions, architectural artifacts participate in the reproduction of social systems of communications. They frame virtually all-social communication systems. All social interactions take place in designed spaces filled with designed artifacts. As the part of communication system of architecture artifacts cannot be evaluated or designed without knowledge system and practical contents.

\section{Epilogue}

This study attempts to discuss architectural design thinking in a reflexive design perspective, which is adopted as a novel research approach in design- and practice-based researches. The study aims to propose a new way of evaluation and re-theming that could provide stimulating opportunities for self-understanding of the basic dimensions of design thinking in architecture and furthermore undertakes a responsibility of providing guidance in design-based research. This novel evaluation approach is named as the "3 A's of Reflexive Design Thinking in Architecture" and intends to uncover new connections and potentials in architectural design thinking. Each dimensions of design thinking; architect, action and artifact were evaluated to propose a new way of thinking in a reflexive perspective for the very well-known themes. In this system, the architect was considered as the reflexive researcher who is not only a creative designer but also as a researcher with the task to construct new theories, models and techniques. Additionally, action was contemplated as the research process itself, an open creative cognitive action. It was shaped through a variety of thinking systems like; delineating, implicating, interpreting, modifying, consolidating and intensifying. These steps, evaluated as the main dimensions of creative cognition system, refer to the design process which occurs as a reflexive thinking action containing an iterative cycle mainly based on self-referencing and evaluation. Finally, the artefact, evaluated as the creative design product, was considered as the part of the communication system within the knowledge and practice of architecture. It is not only a tangible form but also a social, cultural setting, in other words, the reproduction of social systems of communications. Briefly, this study proposes a new evaluation system for design-based research constructed through the reflexive design perspective and emphasizes the significance of the utilization of reflexive design in design-based research in order to ensure subjectivity and self-referencing, which could provide a novel approach in thinking and evaluating creative generation and transformation as well as special forms of cognition.

\section{Acknowledgements}

This study is the part of research project supported by Eskisehir Osmangazi University, Scientific Research Commission with project number: 2017-1678, titled as` Reflexivity in the German Architectural Design Culture, Contemporary Dimensions of Günter Behnisch Architecture `conducted by the author at Leibniz University, Hannover, Germany between August 2017 - April 2018, under the supervision of Prof. Dr.-Ing. habil. Dr. phil. Margitta Buchert .

\section{References}

Anderson, G. L. (1989). Critical ethnography in education: Origins, current status, and new directions. Review of Educational Research, 59(3), 249-270. https://doi.org/10.3102/00346543059003249

Archer, M. S. (2007). Making our Way through the World Human Reflexivity and Social Mobility. Cambridge, UK: Cambridge University Press. https://doi.org/10.1017/CBO9780511618932

Archer, M. S. (2010). Conversations About Reflexivity. Abingdon, Oxon: Routledge. 
Aura, S., Katainen, J., \& Suoranta, J. (2002). Theory, Research and Practice: Towards reflective relationship between theory and practice in architectural thinking. Nordisk Arkitekturforskning, 1, 73-81.

Beck, U., Bonns, W., \& Lau, C. (2003). The Theory of Reflexive Modernization Problematic, Hypotheses and Research Programme. Theory, Culture \& Society, 20(2), 1-33. https://doi.org/10.1177/0263276403020002001

Beck, U., Giddens, A., \& Lash, S. (1994). Reflexive Modernization. Politics, Tradition and Aesthetics in the Modern Social Order. Cambridge: Polity Press.

Bourdieu, P. (1990). In Other Words : Essays Towards a Reflexive Sociology. Stanford, California: Standford University Press.

Bourdieu, P., \& Wacquant, L. J. (1992). An Invitation to Reflexive Sociology. Cambridge: Polity Press.

Brown, H., Sawyer, R. D., \& Norris, J. (2016). Forms of Practitioner Refexivity Critical, Conversational, and Arts-Based Approaches . New York : Palgrave Macmillan.

Buchert, M. (2014). Reflexive Design. Berlin: Jovis Verlag.

Buchert, M. (2016). Praktiken Reflexiven Entwerfens. Berlin: Jovis.

Conway, H., \& Roenisch, R. (2005). Understanding Architecture: An introduction to architecture and architectural history. New York : Routledge. https://doi.org/10.4324/9780203973196

Etherington, K. (2004). Becoming a Reflexive Researcher, Using Our Selves in Research. London, UK: Jessica Kingsley Publishers .

Finlay, L., \& Gough, B. (2003). Reflexivity: A Practical Guide for Researchers in Health and Social Sciences. Oxford, UK: Blackwell Science. https://doi.org/10.1002/9780470776094

Grim, P., \& Rescher, N. (2012). Reflexivity From Paradox to Consciousness. Heusenstamm, Germany: ontos verlag.

Hays, M. (1998). Architecture Theory Since 1968. New York: The MIT Press.

Hays, M. K. (2010). Architecture's Desire: Reading The Late Avant-Garde. Cambridge: MIT Press.

Howe, J., \& Langdon, C. (2002). Towards A Reflexive Planning Theory. Planning Theory, 1(3), 209-225. https://doi.org/10.1177/147309520200100302

Janson, A. (2014). Fundamental Concepts of Architecture. In M. Buchert, Reflexive Design (pp. 104-125). Berlin, Germany: Jovis. https://doi.org/10.1515/9783034608923

Luhmann, N. (1990). Essays on Self-Reference. NEW YORK: Columbia University Press.

Luhmann, N. (1995). Social System. Stanford University Press, Stanford, California.

Luhmann, N. (2000). Art as a Social System . Stanford, California : Stanford University Press.

Mann, S. (2016). The Research Interview Reflective Practice and Reflexivity in Research Processes. NewYork: Palgrave Macmillan.

Piotrowski, A. (2001). On the Practices of Representing and Knowing Architecture. In A. Piotrowski, \& J. W. Robinson, The Discipline of Architecture (pp. 40-60). London: University of Minnesota Press.

Polanyi, M. (1962). Personal Knowledge: Towards a Post-Critical Philosophy . London: Routledge \& Kegan Paul Ltd.

Renier, B., Volker, L., \& Wamelink, H. (2009). The Revival of the Architect. In L. Calabrese, A. Doeschate, A. Geenen, D. Hauptmann, J. Heintz, \& U. Knaack, The Architecture Annual 2007-2008. Delft University of Technology (pp. 88-93). Rotterdam: 010 Publishers.

Roulston, K. (2010). Reflective Interviewing A Guide to Theory and Practice. London: SAGE. https://doi.org/10.4135/9781446288009

Ruby, J. (1980). Exposing yourself: Reflexivity, anthropology, and film. Semiotica, 30(1-2), 153-179. https://doi.org/10.1515/semi.1980.30.1-2.153

Schön, D. (1983). The Reflective Practitioner: How professionals think in action. London: Temple Smith.

Schumacher, P. (2012). The Autopoiesis of Architecture, Vol.2: A New Agenda for Architecture. London: John Wiley \& Sons Ltd.

Shacklock, G., \& Smyth, J. (1998). Being Reflexive in Critical Educational and Social Research. London, UK: Falmer Press.

Silvetti, J. (1998). The Beauty of Shadows. In K. M. Hays, Architecture Theory Since 1968 (pp. 266-282). London, 
England: The MIT Press.

Woolgar, S. (1998). Knowledge and Reflexivity: New Frontiers in Sociology of Knowledge. London: SAGE.

\section{Copyrights}

Copyright for this article is retained by the author(s), with first publication rights granted to the journal.

This is an open-access article distributed under the terms and conditions of the Creative Commons Attribution license which permits unrestricted use, distribution, and reproduction in any medium, provided the original work is properly cited. 